\title{
SOCIAL EFFECTS OF AGRICULTURAL EXPANSION OF LAND USE CHANGE IN CHIBOMBO DISTRICT, CENTRAL PROVINCE, ZAMBIA
}

\author{
Mashandi, F. ${ }^{1 *}$; Banda, K. ${ }^{1}$; Mweemba L. ${ }^{2}$ \\ ${ }^{1}$ Department of Geology, School of Mines, The University of Zambia, P.O Box 32379, Lusaka, Zambia. \\ ${ }^{2}$ Department of Geography, School of Education, The University of Zambia, P.O Box 323879, Lusaka, Zambia. \\ *Corresponding Author
}

DOI: https://doi.org/10.51193/IJAER.2021.7507

Received: 31 Jun. 2021 / Accepted: 06 Jul. 2021 / Published: 11 Nov. 2021

\begin{abstract}
The Zambian agriculture sector comprises crops, livestock, and fisheries. There are three broad categories of farmers: small-scale, medium, and large-scale. Most Zambians are subsistence farmers. Agriculture contributes about 19 percent to GDP and employs three quarters of the population. Domestic production is comprised of crops such as maize, sorghum, millet, and cassava while exports are driven by sugar, soybeans, coffee, groundnuts, rice, and cotton as well as horticultural produce. The Zambia territory is 75 million hectares $\left(752,000 \mathrm{~km}^{2}\right)$, out of which $58 \%$ (42 million hectares) is classified as medium-to high-potential for agriculture production. However, only 15 percent of this land is currently under cultivation. Human influence on the land and other natural resources is accelerating because of rapid population growth and increasing food requirements. Therefore, agricultural intensity generates pressure not only on land resources but also across the whole environment. Even though the forest resources of Zambia are one of the highest in the Southern Africa region (estimates between 47\% - 67\% forest cover) it is decreasing at a rate of between 300,000 ha and 445,000 ha per annum due to agricultural activities and other factors (Ng'andwe et al., 2007; Mukosha, 2006 and Mbindo, 2007). Chibombo district as the study area is a rural district which relies on agriculture as a source of income. Nevertheless, the standard of living in Chibombo district is below the acceptable standard. The study focuses at determining why the socio-economic status of the people in Chibombo district is below the accepted standard of living. The study aims to determine the extent of land use change in Chibombo District. The study intends to clearly determine the impact of social effects of agricultural expansion in Chibombo district by
\end{abstract}


analyzing the drivers of change so as to analyse the socio-economic status and agricultural expansion in Chibombo district.

Keywords: Agriculture, Subsistence farmers, Domestic production, Socio-economic status, Standard of Living, income

\section{BACKGROUND}

The Earth's surface has been modified significantly in recent years by different kinds of land cover/use changes (Meyer and Turner 1994) most of which are as a direct impact by human influence. Typical LULC changes includes forests cover change, impacts on grasslands or rangelands, degradation of wetlands, and changes on tundra and desert ecosystems (MA 2005, Giri 2012,). Globally, the demand for land resources and expansion of technological capacity has significantly altered the natural land cover (Sharma and Tiwari 2010). Expansion of agricultural lands is so far the single most significant driver of land use/cover change in the last five decades (Sharma and Tiwari 2010). Much of the agricultural land has been converted from natural forests, grasslands, and wetlands, which provide valuable habitats for species and ecosystems crucial to the survival of humankind (MEA 2003). Global forest area has decreased from about 53 million square kilometres in 1700 to about 44 million square kilometres at the beginning of the 21 st century. It is estimated that, in the same period, the area covered by savannah and grasslands has decreased globally from 30 to 32 million square kilometres to 12 to 23 million square kilometres (Lambin and Geist, 2006). Recent findings also revealed that the growing global population and associated increase in demand for food has attributed to increase agricultural area to nearly $40 \%$ of the earth's ice free land surface of which had previously been covered by natural vegetation (Ramankutty et al., 2008; Ellis et al., 2010).

Agriculture is a dominant form of land management globally. Rapid population growth as primary driving force connected with increasing food requirements generate great pressure on future land use, environment, natural resources, and ecosystem services. Recent rates of land-use and cover changes are higher than ever. In many developing countries and countries with transition economies, growing demand for food has caused expansion of cropland. Extensive agricultural systems are slowly intensified. Extensive forms of agriculture used in past mainly in Europe and North America were transformed into industrial-style agriculture accompanied by intensification and specialization. The large inputs of fertilizers, pesticides, fossil fuels have large, complex effects on the environment (Slaughter, 2011; Kanianska, 2016). Agriculture releases significant amounts of greenhouse gases and ammonia emission to the atmosphere. It is the single largest user of freshwater resources. Intensive management practices escalating rates of land degradation, soil and water deterioration. The effects on the environment arise at site-specific level but can have impact at local to global levels. Land-cover changes cause the 
International Journal of Agriculture and Environmental Research

ISSN: 2455-6939

Volume: 07, Issue: 05 "September-October 2021"

disappearance of traditional agricultural landscape and are responsible for vegetation modifications which have an impact on regional climate, carbon sequestration, and biodiversity losses. Agriculture also has impact on the natural systems and ecosystem services on which humans depend (Kanianska, 2016).

Future challenges relating to greater pressure on environment, natural resources, and climate change imply that a "business as usual" model in agriculture is not a viable option. Green growth is a new method that places strong emphasis on the complementarities between the economic, social, and environmental dimensions of sustainable development. Thus, the main role of future agriculture is its transformation into good productive but a sustainable system that can be effective for centuries without adverse effect on natural resources on which agricultural productivity depends.

Land cover and land use pattern on earth reflect the interaction of human activities and the natural environment. Human influence on the land and other natural resources is accelerating because of rapid population growth and increasing food requirements. Therefore, agricultural intensity generates pressure not only on land resources but also across the whole environment. Even though the forest resources of Zambia are one of the highest in the Southern Africa region (estimates between $47 \%$ - 67\% forest cover) it is decreasing at a rate of between 300,000 ha and 445,000ha per annum due to agricultural activities and other factors (Ng'andwe et al., 2007; Mukosha, 2006 and Mbindo, 2007).

Chibombo district as the study area is a rural district which relies on agriculture as a source of income. Nevertheless, the standard of living in Chibombo district is below the acceptable standard. The study focuses at determining why the socio-economic status of the people in Chibombo district is below the accepted standard of living. The study aims to determine the extent of land use change in Chibombo District. The study intends to clearly determine the drivers of land use change in Chibombo district. The study aims at investigating the effects of land use change on social-cultural conservation patterns and further aims at determining the social effects of agricultural expansion of land use change in Chibombo district.

\section{MATERIALS AND METHODS}

\subsection{Research Design}

The study intends to adopt a cross-sectional research design, in which it will attempt to understand the patterns, root causes and impacts of land use change. This will entail collecting of a variety of information, and then analyzing the linkages between components of the system to identify causes of the current trends, and to project future changes. The dependent variable of interest to the study is land use change for which the study intends to establish the existence and 
magnitude of causal effects on a number of socio economic independent variables. The study will employ secondary data of Landsat images TM (1996-2016) which will be subjected to unsupervised and supervised classification procedures.

\subsection{Study Area}

The study will be conducted in Chibombo District in Zambia. Chibombo district is situated at $14.65^{\circ}$ South latitude, $28.07^{\circ}$ East longitude and 1149 meters elevation above the sea level. Chibombo is a small community in Zambia, having about 4,477 inhabitants. Chibombo district covers a total area of $8,184 \mathrm{~km}^{2}$ (CSO, 2019).

\subsection{Study Population}

The gender population of Chibombo district as denoted by the Central Statistical office entails $50.3 \%$ are female while $49.7 \%$ are male on the total population of 199,127 . The segmentation of the population in relation to the rural-urban settlement indicated $94.6 \%$ of the population were in the rural parts of the district.

\subsection{Study Sample}

384 head of households from villages that are found within the Chibombo District will be randomly selected. All the names of the heads of various households in the sampled villages will be extracted from the registers that are regularly updated and kept at the District Administration Offices. The names of heads of households will be written on pieces of paper and a random sample will be numbered from 1 up to 384.The sample size was calculated using the formula below from the population size of 199,127 at the sampling confidence level of $95 \%$ and a margin of error at $5 \%$ and indicates that the sample size to be considered in this study would be 384 .

$$
\frac{\frac{z^{2} \times p(1-p)}{e^{2}}}{1+\left(\frac{z^{2} \times p(1-p)}{e^{2} N}\right)}
$$

$\mathrm{N}=$ population size $\mathrm{e}=$ Margin of error (percentage in decimal form) $\mathrm{z}=\mathrm{z}$-score

\subsection{Sampling Techniques}

Simple random sampling will be used to avoid bias in the result and ensure that initial selection of respondents have the same probability of being selected.

\subsection{Data Collection Instruments}


Literature will be reviewed. This will involve reviewing records of the District. It will include publications on research in the area of the study. The researcher anticipates that reviewing documents will help to gather relevant views to the study that otherwise will not be possible to obtain by mere interaction with the study sample. Such publications and documents will include journals, text books and web materials. The documents that will be reviewed include District reports that will be in line with the study topic.Structured questionnaires, field survey, secondary data and field observation will be of consideration.

\subsection{Data Collection Procedure and time line}

\subsubsection{Modelling of transitions of land use change in Chibombo District}

This activity shall involve four activities these include: computation of land use change, determination of land use change rate, integrated land use/cover change rate for the whole catchment, and analysis of the change of land use patterns. Times series Landsat imagery at $30 \mathrm{~m}$ and 28 day spatial and temporal resolution between 1996-2016 will be utilised. In order to achieve this objective, the study will adopt the modelling approach proposed by Peng et al (2008) as has been explained in the following sub-sections.

\section{a) Determination of land use change}

To detect in detail the process of LUCC in Chibombo district during 1996-2016, an analysis of land use change matrix will be conducted through the spatial overlay of the two land use maps of 1996 and 2016 respectively.

The overlay of two land use maps $\mathrm{Ai}^{*} \mathrm{I}$ and $\mathrm{Bi}$ * I keeps to the map algebraic formula (1), which is valid with the number of land use types not more than 10. After the map algebraic operation, a map of land use change, $\mathrm{Ci}^{*} \mathrm{j}$ is derived to represent the types of land use change from time A to time B and associated spatial distribution.

$$
\mathrm{Ci} * \mathrm{j}=\mathrm{Ai} * \mathrm{j} * 10+\mathrm{Bi} * \mathrm{j}
$$

\section{b) Determination of the rate of land use change}

Two kinds of land use change rate will be of focus in this case study, i.e. the change rate of single land use type, and the integrated land use change rate for the whole Chibombo district.

(i) Change rate of single land use type 
As land use dynamic degree for single land use type can quantitatively measure the change of ascertain land use type, the index is recognized as one of the most widely used indices for detecting the land use change rate. It is mostly calculated according to equation (2):

$$
K 1=\frac{U b-U a}{U a} \times \frac{1}{T} \times 100 \%
$$

Where $\mathrm{K} 1$ is land use dynamic degree, measuring the change rate of the target land use type; Ua and $\mathrm{Ub}$ are the area of the target land use type at the beginning and end of the study period respectively; and $\mathrm{T}$ is the study period, which is usually measured with the unit of year. The index of K1 can concisely express the overall characteristics of the change of a certain land use type in the study period, while it is acknowledged that $\mathrm{K} 1$ has missed some information on the spatial process of land use change. Generally speaking, there are three change types for a certain land use type in the process of land use change, i.e. no conversion, conversion to other land use types, and conversion from other land use types. It is obvious that what is measured by the index of $\mathrm{K} 1$ is the integration of the three kinds of change for the target land use type in the study area, and it cannot express the information on each change type directly. Thus, another index for the change rate of single land use type was constructed according to equation (3):

$$
K 2=\frac{\Delta i n+\Delta o u t}{U a} \times \frac{1}{T} \times 100 \%
$$

where $\mathrm{K} 2$ is land use dynamic degree, measuring the change rate of the target land use type; $\Delta$ in and $\Delta$ out are the area of the target land use type conversion from or to other land use types in the study period respectively; and $\mathrm{T}$ is the study period, which is usually measured with the unit of year.

Focusing on the process of land use change, the index of $\mathrm{K} 2$ can effectively reflect the area ratio of the conversion from and to the target land use type. As what the index of $\mathrm{K} 1$ reflects includes the information on the comparison between conversion loss and gain, both $\mathrm{K} 1$ and $\mathrm{K} 2$ are used to measure the change rate of single land use type. In details, the index of K2 quantifies the total "loss or gain" conversion of the target land use type; while the index of K1 reflects the algebraic summation of conversion loss and gain of the target land use type, and the absolute value of K1 measures the extent of the relative difference between conversion loss and gain, with a positive sign of the value of K1 for the dominance of conversion gain from other land use types to the target land use types, and a negative sign for the precedence of conversion loss.

(ii) Determination of the integrated rate of land use change in Chibombo District 
In order to detect the change rate of catchment based land use as a whole, an index of integrated land use dynamic degree will be used in this study, which will be calculated according to equation (4):

$$
L U C=\left(\sum_{i=1}^{n} \Delta L U i \rightarrow j\right) \times \frac{1}{L U} \times \frac{1}{T} \times 100 \%
$$

Where LUC is integrated land use dynamic degree, measuring the integrated land use change rate for the whole region; $\Delta \mathrm{LUi} \rightarrow \mathrm{j}$ is the area converted from land use type $\mathrm{i}$ to land use type $\mathrm{j} ; \mathrm{n}$ is the number of land use types; LU is the total area of the study area; and $\mathrm{T}$ is the study period, which is usually measured with the unit of year.

\section{c) Determination of the change of land use patterns}

The change of land use patterns will be monitored and assessed with the application of landscape metrics. Landscape metrics are ecological indicators used to quantify the composition and spatial configuration of landscapes. Since they not only quantify spatial patterns, but also interpret ecological information hidden in spatial data, landscape metrics can correlate the ecological process and spatial patterns in a landscape.

In this study, two metrics will be selected for the analysis of landscape patterns, these include Shannon's diversity index (SHDI) measuring landscape diversity and area-weighted mean patch fractual dimension (AWMPFD).

\subsubsection{Determinig the drivers of land use change in Chibombo district.}

The datasets required for the study will be generated through both primary and secondary sources, including reports, formal household survey, group discussion with elders, field observations, and informal discussion with individual farmers and development agents (DAs) working at the study landscape. Two phases of field work will be conducted. Both primary and secondary data collection and detailed household surveys, using semi-structured questionnaires, and group discussions will be conducted. Further field work for additional secondary data will be conducted.

\subsubsection{Sampling and household survey}

The household survey will be conducted in representative (villages) of the study area, which are the smallest and lowest level of administration units in Zambia. To generate proper data, selection of respondents will be carried out in stratified sampling techniques. In addition, focused group discussions will be conducted in each village mainly with elders to have a clear view of 
International Journal of Agriculture and Environmental Research

ISSN: 2455-6939

Volume: 07, Issue: 05 "September-October 2021"

drivers of changes during the study period. The survey questionnaires will cover issues regarding socioeconomic characteristics of households, drivers of LULC changes, perception of the local people, and ranking of the drivers. The selection of explanatory variables (drivers) of LULC changes incorporated in the questionnaire will be based on literature and expert knowledge of the area. Other associated information, including crop production and forest and livestock situations will also be explored. Similar types of issues will also be covered during group discussions. Draft maps, with different reference years of the study landscape and aerial photographs, will be printed on paper and served as a discussion basis to facilitate the group discussions.

\subsubsection{Other datasets}

Other datasets of the study area will be obtained from multiple sources, mainly collected and synthesized from published literature, official statistics, policy documents, and on-site measurements. Population data will be obtained from the Central Statistical Office (population of 2010) and District Offices (population of 2019) of the study landscape.

\subsection{Data Analysis Instruments and Procedures}

Combinations of techniques, including descriptive statistics, GIS-based processing, and regression analyses will be employed for data analyses. Descriptive statistics of simple frequency analyses will be used to describe socioeconomic characteristics of households and to summarize their responses and rankings of drivers of the land use changes. Data collected through group discussions and observations will be analyzed qualitatively. Association/differences in perceptions among respondents in different villages concerning drivers of LULC changes will also be investigated using nonparametric test, namely Pearson's chi-square test.

Further, for Geospatial analysis, ERDAS 8.4 software will be used to determine land use change transition, FRAGSTATS 3.3 will be used to compute the selected landscape metrics. While the arc GIS 9.2 based land change Modeller software will be used for change analysis in the Chibombo District.

\section{RESULTS AND DISCUSSIONS}

Agriculture is a dominant form of land management globally. Rapid population growth as primary driving force connected with increasing food requirements generate great pressure on future land use, environment, natural resources, and ecosystem services. Recent rates of land-use and cover changes are higher than ever. In many developing countries and countries with transition economies, growing demand for food has caused expansion of cropland. Extensive agricultural systems are slowly intensified. Extensive forms of agriculture used in past mainly in Europe and North America were transformed into industrial-style agriculture accompanied by 
International Journal of Agriculture and Environmental Research

ISSN: 2455-6939

Volume: 07, Issue: 05 "September-October 2021"

intensification and specialization. The large inputs of fertilizers, pesticides, fossil fuels have large, complex effects on the environment ((Slaughter, 2011; Kanianska, 2016). Agriculture releases significant amounts of greenhouse gases and ammonia emission to the atmosphere. It is the single largest user of freshwater resources. Intensive management practices escalating rates of land degradation, soil and water deterioration. The effects on the environment arise at site-specific level but can have impact at local to global levels. Land-cover changes cause the disappearance of traditional agricultural landscape and are responsible for vegetation modifications which have an impact on regional climate, carbon sequestration, and biodiversity losses. Agriculture also has impact on the natural systems and ecosystem services on which humans depend (Kanianska, 2016).

\subsection{The area available for nature conservation can be represented as:}

Land for nature $=$ Total land area $-($ Agricultural area + Settlements $)$, this view asserts that to maximize the land allocated for nature conservation, the land area used to produce agricultural output must be minimized, taking into account geographic variations in ecological attributes, land quality, and the availability of production factors. At a global scale, the demand for a given agricultural product should be equal to its supply. The required agricultural area is given by the global food equation, for a product Population $x$ (Consumption per capita) $i=$ Agricultural area $i$ $x$ Yieldi, On the supply side, one food product can be replaced by substitutes that decrease the consumption of product i (e.g., seafood or crops with high calories per unit of cultivation). Moreover, for a country c, imports and exports of that product / affect its supply: Population c $\mathrm{x}$ $\left(\right.$ Consumption per capita) $c i=\left[\left(\right.\right.$ Agricultural $\operatorname{areac}_{i} \times$ Yieldc $\left._{i}\right)+\left(\right.$ Importsci - Exports $\left.^{\wedge}\right]$

The demand side of the equation is unlikely to decrease anytime soon as the world population will not stabilize before the second half of the century and consumption per person increases as billions of people move out of poverty. Replacing starchy staples with livestock and horticultural products increases demand for land. Future yield increases will have to first compensate for the prime agricultural land that is converted to other land uses (e.g., settlements) before meeting the increasing demand for food. Countries with sparse land reserves will have either to increase their imports and decrease their exports of food, feed, and fibers to preserve wildlands or acquire land abroad.

\section{CONCLUSION}

Agricultural development is considered the largest contributor of GDP. Due to this significant contribution to GDP, the government of Zambia considers agriculture as the best alternative to mining. Generally, the country aims at achieving poverty reduction through agricultural development. In view of the above, the research aims at greatly contributing to the formation of 
International Journal of Agriculture and Environmental Research

ISSN: 2455-6939

Volume: 07, Issue: 05 "September-October 2021"

agricultural policies that will be aligned to a rational understanding of the trade-offs between food production and reducing environmental degradation. The data will aid policy makers and other stakeholders as they embark on policies that will entail a balance between agriculture expansion and environmental protection. The study intends to clearly determine the impact of social effects of agricultural expansion of land use change in Chibombo district by analyzing the drivers of change so as to analyze the socio-economic status and agricultural expansion in Chibombo district.

\section{ACKNOWLEDGEMENT}

The authors wish to express their gratitude to the RUFORUM Secretariat for the research grant number: RU/2018/GTA/DRG/03. This paper was a contribution to the 2019 RUFORUM $15^{\text {th }}$ Annual General Meeting (AGM).

\section{REFERENCES}

[1] Bürgi, M., Hersperger, A.M., Schneeberger, N., (2004). Driving forces of landscape change - current and new directions. Landscape Ecology19:857-868.

[2] Bürgi, M., Turner, M. G., (2002). Factors and processes shaping land cover and land cover changes along the Wisconsin River. Ecosystems5:184-201.

[3] Chrysoulakis, N., Kamarianakis, Y., Farsari, Y., Diamandakis, M. and P. Prastacos, (2004). Combining Satellite and Socioeconomic data for Land Use Models estimation. In Goossens, R. (Editor), Proc. Of $3^{\text {rd }}$ Workshop of EARSeL Special Interest Group on Remote Sensing for Developing Countries (in press).

[4] FSP, 2004, Forest resources valuation study. Forest Support Programme. Forestry Department, Lusaka.

[5] Land cover change and impact of shrimp aquaculture on the landscape I the Ceuta Coastal Lagoon system, Sinaloa, Mexico. Ocean and Coastal Management. 583-600

[6] Kanianska, R. 2016. Agriculture and its impacts on land use environment, and ecosystem services. DOI: $105772 / 63719$

[7] Muller, D., (2004). From agricultural expansion to intensification: Rural development and determinants of land-use change in the Central Highlands of Vietnam. Tropical Ecology Support Program.

[8] Ng'andwe, p, Muimba, A, Banda, A.K, Mwitwa, J. P and Shakacite, D. 2007, Forest, revenue, concession systems and the contribution of the forestry sector to poverty reduction and Zambia's economy: An analytical report prepared for FAO in conjunction with the Forestry Department, Ministry of Tourism, Environment and Natural Resources. 